\title{
A EMANCIPAÇÃO CULTURAL E O DESENVOLVIMENTO HUMANO: A LINGUAGEM MUSICAL COMO PRESSUPOSTO FORMATIVO EM UM CURSO DE PEDAGOGIA ${ }^{1}$
}

\section{CULTURAL EMANCIPATION AND HUMAN DEVELOPMENT: THE MUSICAL LANGUAGE AS A FORMATIVE ASSUMPTION IN A PEDAGOGY COURSE}

\author{
Maria Lucia Marocco Maraschin* \\ ORCID: https://orcid.org/0000-0002-9322-5342 \\ Daniela Romansin Lazaretti** \\ ORCID: https://orcid.org/0000-0003-2549-2841
}

\section{RESUMO}

O movimento analítico descrito reflete uma experiência formativa vinculada a um projeto de cultura desenvolvido em decorrência da demanda de estudantes do curso de Pedagogia da UFFS - Campus Chapecó. O projeto foi aprovado em edital institucional de incentivo à cultura e executado nos semestres 2018.2 e 2019.1, tendo como público as/os acadêmicas/os do Curso. O projeto realizado se aportou em pesquisas e proposições a partir das quais se construiu uma possibilidade formativa inicial, com estudos e vivências por meio de oficinas. As(os) partícipes deste exercício sinalizaram a relevância da iniciativa, dadas as contribuições ao pensar e ao fazer docente em relação à educação musical e às demais linguagens. Este exercício aponta para a necessidade da presença de discussões acerca de tais linguagens no processo de formação inicial e continuada de professoras(es) que atuam na Educação Infantil e nos Anos Iniciais do Ensino Fundamental.

Palavras-chave: Linguagem musical; Musicalidade; Musicalização; Formação inicial.

\begin{abstract}
The analytical movement described reflects a formative experience bounded by a cultural project developed as a result of induced demand coming from students of the Pedagogy course at UFFS (in the Portuguese acronym) Chapecó Campus. The project was approved in an institutional public notice to encourage culture and it was carried out in the second semester of 2018.2 and first semester of 2019; the target population were the undergraduate students of the course. The project was based on research and propositions, from which an initial formative possibility was built, with systematic studies and experiences in the form of workshops. The students involved in the activities indicated the relevance of such initiatives, given the contributions to teachers' way of thinking and making in relation to the possibilities and the potential of music education and other languages. This exercise points to the need of discussions about such languages in the process of initial and continuing education of teachers working in Early Childhood Education and Early Years of Elementary School.
\end{abstract}

Keywords: Musical language; Musicality; Musicalization; Initial education.

Data recebimento: $24 / 05 / 2020$

Data de aceite: $11 / 09 / 2020$
* Professora da Universidade Federal da Fronteira Sul (UFFS) Campus Chapecó, Santa Catarina - Brasil. E-mail: maraschin.marialucia.ml@gmail.com

** Pedagoga. Universidade Federal da Fronteira Sul (UFFS) Campus Chapecó, Santa Catarina - Brasil. E-mail: daniela.lazaretti@hotmail.com 


\section{Introdução}

Trata-se de um relato de experiência que sistematiza e reflete ações de cultura e de extensão viabilizadas por meio de um projeto de cultura, que abordou, embora de maneira inicial, aspectos formativos da linguagem musical no curso de Pedagogia da Universidade Federal da Fronteira Sul (UFFS) - Campus Chapecó. O projeto nominado "Musicalidade e Musicalização em espaços educativos: processos de emancipação cultural" foi aprovado em edital institucional de incentivo à cultura, o que garantiu a participação de uma bolsista durante a organização e o desenvolvimento da proposta. O projeto teve duração de um ano e foi desenvolvido durante o segundo semestre de 2018 e primeiro semestre de 2019, tendo como público-alvo as(os) acadêmicas(os) do curso de Pedagogia da UFFS - Campus Chapecó.

Este projeto se originou por demanda induzida proveniente de estudantes que, em decorrência de inserção em outros espaços educativos, sinalizaram o reconhecimento da linguagem musical no processo de desenvolvimento e de aprendizagem das crianças e dos profissionais docentes. Em razão disso, ao identificarem e pontuarem o silenciamento das discussões e das práticas acerca da linguagem musical na matriz curricular do curso de Pedagogia, trouxeram o desafio desta incursão junto a este.

Isso posto, mediados pela professora dos Componentes Curriculares de Alfabetização, foi possível construir uma alternativa, a priori experimental, para a qual conseguimos apoio institucional. Esta demanda veio/vem ao encontro das necessidades formativas decorrentes da linguagem musical, tendo em vista o contexto de atuação do pedagogo e as contribuições potenciais desta linguagem para o processo de desenvolvimento, aprendizagem e formação integral do ser humano, salvaguardado como princípio da educação integral.

Assim, o desenvolvimento deste projeto objetivou proporcionar um espaço formativo para que as(os) licenciandas(os) do curso de Pedagogia acessassem conhecimentos teóricos e práticos acerca da linguagem musical no processo formativo pessoal e profissional, permitindo também ampliar o repertório musical para fins educacionais e de apreciação, assim como de compreender que a linguagem musical e seus processos são aspectos inerentes à natureza humana e à formação integral dos sujeitos.

A busca e a constituição de referenciais específicos da linguagem musical permitiram a compreensão de alguns outros conceitos que transversalizam as conexões destes saberes e suas interfaces formativas, marcadas na atualidade pelas discussões da diversidade e da interdisciplinaridade. A diversidade nos coloca em sintonia com o ser humano e sua realidade, e a interdisciplinaridade induz a posturas diferenciadas de acolhimento, de respeito às singularidades do outro, seus saberes e as possibilidades que daí advêm.

Optamos por compreender alguns conceitos da linguagem musical, sem adentrar especificamente ao conhecimento mais profundo da área, dado o respeito e a complexidade do referencial que lhe é devido. Como exercício inicial, o fizemos com o propósito de 
sensibilizar para a busca da sonoridade, da acuidade, da escuta atenta ao mundo que nos cerca, em suas múltiplas possibilidades, e da percepção e compreensão das contribuições que podem ser possibilitadas, por meio da linguagem musical, nos processos de desenvolvimento e de aprendizagem.

\section{Olhares e conceitos que circunscrevem a sala de aula e a vida}

A música não é um fator externo em relação ao homem - provém do seu interior, é inerente à sua natureza. Ela está presente em todo o universo, inspirando a experiência musical humana. Trata-se da segunda linguagem materna. Por esse motivo, toda criança tem direito a uma educação musical que lhe possibilite desenvolver o potencial de comunicação e expressão embutido nesta linguagem. (ÁVILA; SILVA, 2003, p. 76, grifo do autor).

Ao concebermos e assumirmos a música como algo inerente à natureza humana, damos a ela o status de direito, assumimos seu potencial e nos debruçamos sobre os aspectos formativos necessários a esta perspectiva. A sinalização efetuada pelas autoras de que a música é concebida como segunda linguagem materna dá-se devido à importância a ela atribuída no e para o desenvolvimento desta, pontuando os estímulos, a sensibilização necessária à construção deste caminho pela linguagem musical. Assim, o ouvir e o sentir, os sons e os ritmos, os silêncios, os ruídos vão nos potencializando referenciais e repertórios materializados na e pela vida que pulsa dentro de todo e qualquer ser humano.

Neste entendimento, Bellochio e Figueiredo (2009) dão destaque ao papel da escola como espaço e contexto potencializador da educação musical, tendo em vista que "se a música faz parte da experiência humana em diversos momentos da vida e com diversas funções, também faz parte da escola" (BELLOCHIO; FIGUEIREDO, 2009, p. 37). Além disso, a presença da linguagem musical nos currículos escolares tem respaldo legal, a partir das diretrizes e referenciais curriculares que regem a Educação Básica e em legislação específica, embora os compromissos com sua efetividade distem do intencionado, no que se refere aos compromissos com a formação de professoras(es).

A ocupação com esta especificidade se dá quando temos o privilégio de conviver com profissionais que tiveram acesso a esta possibilidade conectiva de ter a música em seus referenciais educativo/formativos. Figueiredo (2005) destaca que a ausência da linguagem musical nos processos de formação docente e, por conseguinte, nos processos pedagógicos da Educação Básica tem um caráter cíclico, pois raramente quem não teve a oportunidade de vivenciar experiências significativas no contexto da educação musical compreende sua importância, suas possibilidades formativas e sua contribuição para a vida, em atenção ao desenvolvimento humano integral. 
Para Maffioletti (2010), a musicalidade é a capacidade humana para perceber, reconhecer, memorizar, interpretar e atribuir significado aos sons e suas peculiaridades. Estas capacidades dependem de condições biológicas e das possibilidades oferecidas pelo contexto sociocultural. Aqui reiteramos a relevância e a função social da escola para referenciar esta possibilidade formativa, porém, para que isso aconteça, as opções culturais precisam ser efetuadas em prol desta possibilidade.

$\mathrm{Na}$ mesma perspectiva, trazemos a compreensão da musicalização como processo de construção da linguagem musical, que "começa espontaneamente, de forma intuitiva, por meio do contato com toda a variedade de sons do cotidiano, incluindo aí a presença da música" (BRITO, 2003, p. 35). Neste sentido, compreendemos que a línguagem musical, por meio da musicalização, pode potencializar e contribuir para o processo de desenvolvimento integral, ao favorecer a sensibilidade, a criatividade, a imaginação, a memória, a atenção, a autodisciplina, a concentração, o respeito ao próximo, a socialização, a afetividade, a motricidade etc. (BRÉSCIA, 2011).

Neste entendimento, buscamos em Bellochio, Weber e Souza (2017) a argumentação e o destaque para a necessidade de formação específica para o pedagogo, tendo em vista que o seu fazer docente se dá na Educação Infantil e nos Anos Iniciais do Ensino Fundamental, na maioria das vezes, de forma unidocente, tendo as múltiplas linguagens para serem referenciadas. O destaque e o cuidado com a línguagem musical dar-se-ão se lhe forem oportunizadas condições mínimas de conhecimentos teórico-práticos, os quais lhe serão subsidiários.

\section{Aspectos metodológicos da prática em discussão}

A proposição metodológica em discussão corrobora uma das afirmações de Nóvoa (2007), a de que a formação de professoras(es) deve advir de dentro da profissão, de dentro da atuação, na relação entre os pares. A relação com os pares e as incursões efetuadas pelas(os) estudantes sinalizaram a necessidade de que, na condição de formadoras(es) de professoras(es) inseridos e comprometidos com um curso de formação de professoras(es), fizéssemos desta demanda uma intencionalidade possível. Com intuito de promover tais atividades formativas, optamos pelo desenvolvimento de oficinas. De acordo com Candau (1999, p. 23), a oficina enquanto estratégia de ensino-aprendizagem deve ser compreendida como uma "construção coletiva de um saber, de análise da realidade, de confrontação e inter-câmbio de experiências".

Neste contexto, Paz (2000) também contribui definindo, mais especificamente, o que são oficinas de música. Segundo a autora, estas estão compreendidas em um vasto campo de atividades que envolvem a educação musical e ocorrem por meio da manipulação de objetos sonoros de forma individual ou em grupo, o que leva ao conhecimento das capacidades criativas e inventivas existentes em todos nós, levando, assim, ao autoconhecimento e à realização pessoal. Portanto, vivenciar e experienciar os sons e suas possibilidades a partir dos 
próprios referenciais é fundamental para o processo proposto. Neste movimento, o participante percebe e compreende a sua própria musicalidade, além de compreender a flexibilidade no planejamento e na vivência das ações planejadas (PAZ, 2000).

O propósito central da realização de oficinas de música, musicalidade e musicalização se ancorou na sensibilização dos(as) participantes em relação à temática e suas possibilidades. Ainda subsidiadas por Paz (2000), damos destaque a alguns princípios formativos apresentados pela autora, tais como: a sensibilização e a conscientização do mundo sonoro do indivíduo; a identificação e manipulação dos parâmetros do som - altura, duração, timbre, intensidade, etc.; a descoberta de sons corporais, vocais; a experimentação de objetos sonoros; a construção e invenção de novos instrumentos; a experimentação e improvisação; trabalho individual e em grupo; exercícios de apreciação e percepção sonora.

O olhar/ação do professor(a) é fundamental para o crescimento do(a) aluno(a), e ele não pode ser falso, porque implica em outras sensibilidades; a(o) outra(o) sente, percebe, é influenciado por nós. Afinal, o(a) outro(a) e nós sentimos o nosso corpo, com todos os nossos sentidos com a pele, com o toque, com o olhar, todos(as) temos muitas formas de captar o mundo à nossa volta, o nosso papel é muito importante (TRINDADE, 2000, p.12).

Isso ratifica uma afirmação clássica de Freire (1997, p. 160) acerca do fazer docente, "ensinar e aprender não podem dar-se fora da procura, da boniteza e da alegria".

\section{Dos propósitos da ação aos resultados possíveis}

\section{Organização, Planejamento e Desenvolvimento}

Com o propósito de darmos materialidade e promovermos espaços formativos ao demandado, a fim de alcançarmos os objetivos propostos, realizamos estudos acerca da linguagem musical tendo em vista compreender o lastro que dela decorre e suas implicações na atuação e na formação docente na Educação Infantil e nos Anos Iniciais do Ensino Fundamental. As leituras e as discussões efetuadas serviram de aporte teórico-prático para o planejamento e o desenvolvimento de oficinas, que abordaram a linguagem musical e suas especificidades no contexto educacional, possibilitando estudos e vivências práticoreflexivas sobre a música e sua presença no contexto de formação e atuação docente, tendo em vista os processos de desenvolvimento e de aprendizagem das crianças, na maioria das vezes efetuados por pedagogos sem formação específica na área da educação musical.

Nos exercícios em análise, foram planejadas, executadas e avaliadas três oficinas. A mediação formativo/avaliativa em todas as atividades relatadas deu-se pela professora coordenadora do projeto, pela acadêmica bolsista e por duas acadêmicas voluntárias, sendo 
uma delas musicista e educadora musical. Ressaltamos a presença, contribuição e olhar crítico da musicista, vez que sua formação específica ampliou significativamente as possibilidades vivenciadas pelos grupos. Salvaguardamos aqui a importância formativa específica para a sinalização e o cuidado com a apropriação da linguagem musical.

A primeira oficina foi desenvolvida em quatro encontros de 4 horas/aula cada, totalizando 16 horas de formação. O objetivo central desta proposição foi sensibilizar o grupo em relação à presença da linguagem musical na vida e no cotidiano educacional, dando-lhe visibilidade por meio de estudos já realizados e vivências teórico-práticas acessadas.

O público deste exercício foram acadêmicas(os) vinculadas(os) ao Programa Institucional de Bolsas de Iniciação à Docência (PIBID) do curso de Pedagogia, inseridas(os) em escola da rede pública, em turmas do $1^{\circ}$ ao $5^{\circ}$ ano, dispostas(os) conosco a compreenderem os pressupostos da linguagem musical para validarem nossa discussão. Nesta vivência inicial, destacamos o reconhecimento da necessidade e a importância da linguagem musical, dado sua quietude no cotidiano da sala de aula dos Anos Iniciais do Ensino Fundamental, destaque efetuado pelas(os) estudantes, além das evidências empíricas do seu uso normalmente como pretexto.

A segunda e terceira oficina foram desenvolvidas em 8 encontros de 4 horas/aula, totalizando uma carga horária de 32 horas cada. Essas oficinas foram executadas com 2 grupos distintos de acadêmicas do curso de Pedagogia, a partir de práticas similares organizadas em turnos e horários distintos, respeitando-se as peculiaridades dos grupos: uma oportunizada durante a semana e outra aos sábados.

O planejamento e o desenvolvimento das oficinas se nutriram de movimento teórico-prático, possibilitando estudos e vivências aos grupos. Neste contexto, no início dos encontros eram promovidas discussões atentas às temáticas evidenciadas em leituras previamente indicadas ou desenvolvidas naquele momento, e posteriormente eram realizadas práticas relacionadas ao tema em discussão.

Os assuntos abordados durante os encontros envolveram a compreensão e as concepções de música, musicalidade e musicalização, os parâmetros do som (timbre, densidade, altura, intensidade e duração) ${ }^{2}$, o reconhecimento e a classificação dos instrumentos musicais, alguns aspectos introdutórios à teoria musical, a música no contexto da Educação Básica (Anos Iniciais e Educação Infantil) como promotora de práticas interdisciplinares, a formação docente para atuação no contexto da educação musical e as contribuições da linguagem musical para o desenvolvimento cognitivo e integral dos sujeitos. Os compromissos éticos dos grupos envolvidos permitiram avanços expressivos na compreensão, na busca de referenciais e na construção de alternativas para ampliar o repertório ensejado.

As atividades práticas desenvolvidas focaram o desenvolvimento da percepção sonora, da apreciação de músicas da MPB e de outras culturas e países, com o objetivo de 
aumentar o repertório musical das(os) participantes, e proporcionaram a participação em brincadeiras de roda e brinquedos cantados, brincadeiras que envolviam a percepção e a identificação dos parâmetros do som, percussão corporal, construção de instrumentos sonoros com materiais alternativos, exploração dos instrumentos criados e sonorização de histórias.

As proposições desenvolvidas, metodologicamente, foram exercícios individuais e grupais, promovendo um tempo/espaço de formação para as(os) participantes, com vivências sistemáticas da e com a linguagem musical, objetivando também sensibilizálas(os) e instrumentalizá-las(os) de forma teórico-prática para a adoção desta linguagem no cotidiano, explorando possibilidades em suas atuações enquanto professoras(es) da Educação Infantil e dos Anos Iniciais do Ensino Fundamental.

Considerando que a escola e a universidade são espaços de formação coletiva, o processo relatado foi sendo construído. Estudamos, conhecemos e acessamos diferentes experiências realizadas em diversos níveis de ensino. Na sequência, fomos construindo uma proposta de sensibilização, dada a fragilidade e a quietude identificada acerca da problemática que nos mobilizou. Em razão disso, nossa primeira oficina, junto às(aos) pibidianos ocorreu em caráter experimental. Vivenciada e validada pelos nossos pares, colegas e professoras(es), fizemos novas inserções e qualificações, tendo em vista a materialidade do que aqui refletiremos.

Iniciamos o trabalho das duas oficinas, consideradas como básicas para este exercício de reflexão, com a apresentação individual de cada um das(os) partícipes. Cumprida esta etapa, a tarefa foi de que cada integrante do grupo apresentasse alguns indicadores de sua relação com a linguagem musical, a partir de suas percepções.

$\mathrm{Na}$ sequência, realizamos o estudo do texto "A linguagem musical e o desenvolvimento das múltiplas inteligências: um olhar sobre a educação infantil”, de Kátia Regina dos Santos Castro (2016). Posteriormente, propusemos o desenvolvimento de algumas vivências, sinalizando a importância do grande instrumento musical, que é o nosso corpo. Para isso, foram desenvolvidas algumas atividades práticas, tais como: "Marchinha de Noé" (COSTA, 2013), "A carrocinha", "O jipe do padre" e "Jeito diferente" (DAREZZO, 2011). São músicas e atividades presentes no cotidiano das crianças, porém elas têm sido silenciadas na contemporaneidade, dadas as condições e as ferramentas tecnológicas que vêm ganhando a simpatia de ambos, professor(as)es e crianças.

O que merece destaque nesta participação é que as estudantes, professoras em formação vinculadas a diferentes fases do curso, apresentam uma rigidez corporal, associada ao ritmo, à vivência do som e à disponibilidade para a entrega nas atividades em desenvolvimento. Trata-se de uma geração de estudantes de 18 a 35 anos. Nossa indagação é: o que justifica a rigidez corporal à entrega, à vivência da música? 
Após a realização descrita, fizemos um debate sobre a apreciação musical, fundamentado na canção hebraica Zemer Atik descrita no livro De todos os cantos do mundo (PRIETO; PUCCI, 2008). Desta proposição, destacamos a dificuldade em silenciarmos para nos entregarmos a um exercício de escuta. Neste sentido, inúmeras perguntas permanecem: Por que temos resistência à apreciação? Por que o silêncio nos causa desconforto, mesmo que seja para ouvir o que naturalmente não ouvimos?

No segundo encontro foram discutidos, apresentados e retomados os conceitos de música, musicalidade e musicalização, a partir dos conhecimentos do grupo e incursões teóricas já acessadas. Além disso, foram abordados ainda os parâmetros do som: altura, intensidade, timbre, duração e densidade. Foi proposta e desenvolvida neste encontro uma dinâmica de estudo dirigido sobre o texto "A música como estratégia utilizada na Educação Infantil e promotora da interdisciplinaridade: um olhar singular", de Cláudio Alves Siqueira e Evandro Luiz Soares Bonfim (2017).

As atividades práticas desenvolvidas com o grupo ocorreram em torno dos parâmetros do som: identificação de timbres com sons em movimento, brincadeira de vivo ou morto com a altura dos sons, caça ao tesouro e canto explorando a intensidade dos sons, roda de conversa e medição dos sons para abordar o parâmetro duração. Por fím, como proposta de apreciação musical, ouvimos os concertos "Primavera" e "Inverno", da obra "As quatro estações", de Antônio Vivaldi ${ }^{3}$. A apreciação foi acompanhada da produção de um desenho individual, representando os concertos e as sensações evocadas por eles, articulada à discussão da estação do ano caracterizada pela notação musical percebida durante a apreciação. Na sequência, realizamos a socialização das representações do grupo.

O terceiro encontro teve como foco central o cantar e o falar no processo de desenvolvimento da linguagem. Para tanto, nos ancoramos no texto "Antes de falar as crianças cantam: considerações sobre o ensino de música na educação infantil", de Guilherme Romanelli (2014). Tal estudo foi dirigido por questões norteadoras, as quais remeteram o grupo a pensar: Se a música é importante em suas diferentes sintonias, como estes referenciais comparecem na educação infantil e nos anos iniciais do Ensino Fundamental? Que exercícios de escuta musical fazemos com as crianças nas instituições escolares? As indagações efetuadas não necessariamente requerem/requeriam respostas; demandavam, outrossim, reflexão sobre o processo formativo para o exercício da aprendizagem da música, da musicalidade e da musicalização.

Na sequência ao processo de discussão e suas contribuições para o fazer docente no contexto da linguagem musical, foram desenvolvidas com o grupo algumas atividades práticas que envolviam parlendas. Na sequência, foram realizadas atividades em torno das canções/brincadeiras "Escravos de Jó", "Sambalelê", "Pezinho" e "De abóbora faz melão". As atividades propostas buscam ativar e aprimorar a sensibilidade, a coordenação motora, a discrição auditiva, dentre outras particularidades inerentes ao processo de desenvolvimento 
e de aprendizagem com a linguagem musical. A atividade de apreciação musical neste dia foi feita com a canção "Koi txangaré", do livro De todos os cantos do mundo, autoria de Prieto e Pucci (2008).

No quarto encontro, atuamos na compreensão e no desenvolvimento de especificidades da linguagem musical e suas particularidades: notas, pautas, claves etc. Como toda a linguagem, esta tem símbolos, os quais precisam ser conhecidos, pelo menos de uma forma mais ampla, ante a complexidade das suas especificidades, tal como uma partitura musical. Dentre a formação necessária e as práticas musicais a serem propostas em sala de aula, discutimos algumas questões com professoras não especialistas em música. $\mathrm{Na}$ sequência, exploramos as diversas formas de cantar a canção "Cai, cai balão", propostas no texto "Cai, cai balão... Entre a formação e as práticas musicais em sala de aula: discutindo algumas questões com professoras não especialistas em música" (BELLOCHIO; FIGUEIREDO, 2009), envolvendo e explorando ritmos, parâmetros do som, percussão e expressão corporal, sílabas e vogais, etc., estabelecendo conexões com o processo de alfabetização.

$\mathrm{Na}$ sequência, inspirados na proposta de Almeida (2009, p. 180), foram elaborados com o grupo, a partir de instrumentos musicais produzidos, alguns arranjos sonoros com a utilização de paus de chuva e clavas, tendo como base a canção "Canto do povo de um lugar", de Caetano Veloso. A atividade e seu arranjo musical enfatizaram o ritmo e os tempos da música. Na sequência, desenvolvemos com o grupo a proposta de desenhar os sons que ouviam. Tais sons foram emitidos por instrumentos sonoros e representados pelo grupo em folhas A4. Ao concluirmos a atividade, as produções foram socializadas com o grupo. Outra proposição realizada neste encontro foi a brincadeira "Pipocas dançantes", do grupo Palavra Cantada, buscando destacar a importância da expressividade e do movimento corporal, articulados ao ritmo, à atenção e à memória, dentre outros aspectos.

No primeiro momento do quinto encontro, nos fundamentamos com o estudo do texto "As cantigas de roda no contexto da Educação Infantill, de Cleidiane de Oliveira Silva e Paula Almeida de Castro (2016). O intuito foi enfatizar as especificidades e as contribuições das cantigas de roda para a formação e o desenvolvimento humano. Após o estudo, brincamos e realizamos a socialização de algumas brincadeiras de roda de infância, tais como: "A linda rosa juvenil", "Passa a peneira", "Bambu", "Periquito maracanã", "Roda pião", "Imitando os bichos", do grupo Palavra Cantada, e a atividade de percussão corporal Ua tatá e Aram Sam.

O sexto encontro foi destinado à elaboração de objetos sonoros a partir dos materiais trazidos pelo grupo. Teve como referencial de estudo o texto "PIBID Música na Educação Infantil: Uma experiência interdisciplinar a partir da construção de instrumentos musicais e objetos sonoros com materiais alternativos", de Renata Mariano Landgraf (2016). Os objetos confeccionados pelo grupo neste exercício foram: cordofones, aerofones, idiofones e membranofones. 
A produção de instrumentos sonoros, além de ter se constituído em um exercício coletivo e colaborativo oportunizado pela troca de materiais e pela própria produção, promoveu aos sujeitos envolvidos a vivência de elaborações sonoras surpreendentes sintonizadas com os aportes musicais definidos, tais como: a improvisação, as constituições melódicas ambientais e musicais, os arranjos típicos de uma musicalidade que carregam culturas e referenciais culturais. A vivência referenciada chancelou os propósitos do exercício, oportunizando a criação e ativação da imaginação criadora do(a) professor(a) e dos seus(suas) interlocutores(as).

O sétimo encontro enfatizou a sonorização de histórias com os materiais construídos pelo grupo no encontro anterior. Inicialmente, foi feito o estudo do texto "Era uma vez... entre sons, músicas e histórias", de Maria Cristiane Deltregia Reys (2011), que destaca as contribuições da autora no contexto da sonorização de histórias, planejamentos e possibilidades. Considerando a peculiaridade e a importância da temática, acessamos alguns vídeos de histórias sonorizadas, tais como: "A estrela do mar", sonorizado pela cantora, compositora e educadora musical Bia Bedran, com o objetivo de demonstrar ao grupo algumas possibilidades de exploração dos instrumentos produzidos para a proposta de sonorização.

No oitavo encontro, retomamos as discussões conceituais de música, musicalidade e musicalização, a fim de situarmos sua presença/ausência na nossa vida pessoal e profissional, e sua importância no processo de desenvolvimento das crianças e nos processos educativos escolares, evidenciando as possibilidades formativas desencadeadas por meio da oficina. Reiteramos as contribuições e os conhecimentos necessários e constitutivos da linguagem musical, dado que é o pedagogo que faz a iniciação escolar da criança, apresentando-lhe formalmente esta linguagem. A sonorização de histórias, a sonoridade corporal, ambiental, os sons da natureza, das aves, a música em seus diferentes ritmos, gêneros etc., corporificados na produção de instrumentos, são convites à adesão que se faz necessária para assumirmos a linguagem musical nas suas singularidades.

Desenvolvida e avaliada a proposta em discussão, efetuamos uma exposição dos materiais sonoros produzidos no decorrer das oficinas, para experimentação destes, junto aos estudantes do curso de Pedagogia. O desafio desta experiência nos impulsiona a seguirmos na caminhada de apreensão iniciada, dados os impactos descritos e os chamamentos que traduzem.

\section{Impactos e problematizações que seguem para o fazer formativo}

Os impactos das incursões efetuadas nestes exercícios analíticos foram mensurados por meio de um instrumento de avaliação descritiva e roda de conversa ${ }^{4}$, o que objetivou buscar as compreensões decorrentes das interações efetuadas, bem como a sinalização de novos indicadores de demanda para a problematização atendida. 
Neste sentido, vale destacar que o maior impacto adveio da sensibilização e do reconhecimento da importância da linguagem musical na prática docente, dadas as percepções e as contribuições desta, para os processos de aprendizagem, desenvolvimento e formação humana. De acordo com as(os) partícipes, ampliar as compreensões e as possibilidades do uso da linguagem musical na prática educativa, assim como possibilitar o contato do grupo, mesmo que em caráter inicial, com vivências em práticas de musicalização, com a produção de instrumentos sonoros e com o acesso aos materiais de leitura decorrentes de pesquisas e de reflexões, oportunizaram ao grupo o contato com a linguagem musical e algumas possibilidades que a cercam.

Dentre os diferentes destaques efetuados neste exercício analítico, cabe-nos ressaltar as duas possibilidades avaliativo/formativas subsidiárias para a qualificação do realizado: o uso de instrumento e a realização de roda de conversa. A concepção de avaliação subsidiária nestes exercícios, assumida como processo de escuta atenta, relação dialógica e processo de auto avaliação, onde ambos os envolvidos, proponentes e partícipes, corroboram com o repensar, com o aprofundar, com o refazer, de acordo com o proposto por Romão (2002) em consonância com a perspectiva freireana. Este entendimento, considera que os saberes trazidos pelos sujeitos, em conexão com os conhecimentos historicamente elaborados pela humanidade, articulam-se às necessidades de elaboração e reelaboração de novos conhecimentos, por meio da interação entre estes.

Outro destaque relativo à avaliação e que contribuiu sobremaneira neste exercício foram os pressupostos da Análise Textual Discursiva apresentada por Moraes e Galiazzi (2006), referendada como espaço de reconstrução e produção de significados sobre o refletido, qualificando a participação do pesquisador extensionista, permitindo-lhe releituras.

Nesta perspectiva, alguns indicadores descritos nos permitem afirmar que a mobilização para processos educativos diversos requerem disponibilidade por parte de interlocutores dispostos a fazer novas travessias. Abstraímos parte de alguns excertos dos registros dos processos de avaliação realizados junto às(aos) partícipes das propostas formativas para destacar as contribuições e as possibilidades evidenciadas por elas(eles).

[...] aprendi a produzir instrumentos sonoros, compreendi conceitos aos quais nunca tinha tido acesso ${ }^{5}$ [...] eu não sabia [...] nós docentes temos que saber os conceitos básicos para também possibilitar melhorias de compreensão às crianças. $\left(E^{6}\right)$. A oficina foi um exercício muito profissional, ampliou nossa visão como futuras pedagogas (os). Estes exercícios devem ser oferecidos ainda nas fases iniciais [...] para já levarmos esse olhar diferente no estágio e na sala de aula, depois da caminhada formativa. (F). [...]nós conseguimos aprender muitas coisas, todas as atividades foram enriquecedoras, elas nos ajudaram ver o que nós podemos fazer na sala de aula, além de ensinar e educar de um jeito diferente, usando todas as ferramentas possíveis, particularmente a linguagem musical. $(G)$ 
Gostei muito de produzir e de vivenciar o uso dos instrumentos sonoros. (H). [...] as possibilidades de exploração sonora é uma das coisas que mais marcou. [...] (J). [...] reconheci a importância e a influência que a música traz para as crianças e a importância que ela tem, então foi uma brilhante oportunidade. (O). [...] A oficina serviu para alertar a gente não só sobre a música, mas também acerca das outras linguagens invisibilizadas. [...]. A oficina se constituiu num leque de opções, e possibilidades. (Q).

Os excertos dos relatos explicitam, em parte, o processo realizado junto às/aos estudantes, no concernente à linguagem musical e suas contribuições para a formação pessoal e profissional, bem como para a constituição do desejo de se apropriar, aprofundar os conhecimentos relativos à linguagem musical, como linguagem central, no bojo das múltiplas linguagens. Outro aspecto a ser destacado foi o reconhecimento de que muitos dos instrumentos sonoros estão na natureza e de que sua produção/percepção pode e deve envolver as crianças, recolocando o professor(a) como um dos sujeitos que protagoniza o fazer docente e que aprende no processo de mediação desta construção junto à criança. $\mathrm{O}$ destaque, ainda, se dá acerca da necessidade e a importância da formação conceitual, da formação teórica da especificidade da linguagem musical. Há conceitos, referenciais, práticas e processos disponíveis que devem ser utilizados para auxiliar a criança e o(a) professor(a) no desenvolvimento-aprendizagem da linguagem musical.

O que percebemos e que merece destaque neste exercício é a sincronia de um fazer musical, que revela preferências, percepções estéticas peculiares, como as composições e os arranjos distintos, características também de grupos distintos. Trata-se de um processo de ensinar e aprender, de reflexão, de autorreflexão, enfim, de aprendizagem social de relações entre professoras(es) e alunas(os). De acordo com Pérez Gómez (1998), cada exercício, cada grupo social, cada sala de aula tem vida própria e o(a) professor(a) tem um papel fundamental na organização dos processos de ensino-aprendizagem, razão que justifica a necessidade de subsídios múltiplos à sua formação. "A função do(a) professor(a) será facilitar o surgimento do contexto de compreensão comum e trazer instrumentos, procedentes da ciência, do pensamento e das artes para enriquecer, esse espaço do conhecimento compartilhado" (PÉREZ GÓMEZ, 1998, p.64).

\section{Considerações finais}

O projeto apresentado e refletido nesta produção teve como origem a demanda sinalizada por um grupo de acadêmicas em fase final do curso de Graduação em Pedagogia ao evidenciarem a ausência de abordagens acerca da educação musical no contexto do Curso. O diálogo sistemático com os interlocutores da universidade, a escuta efetuada marcada pela problematização das diferentes linguagens traduziram-se nesta possibilidade, 
relatada no decorrer deste exercício analítico. Estudar a linguagem musical significou dar abertura à diversidade de linguagens que igualmente é demandada na e pela sociedade contemporânea.

Por meio das incursões possibilitadas durante a materialização da proposta desenvolvida e seu estudo, pudemos destacar que a linguagem musical, para além das especificidades que lhe são peculiares, nos apresentou categorias e perspectivas, tais como a sonorização de histórias, a educação para a sensibilização, o reconhecimento da diversidade sonora e diversidade cultural, dentre outros aspectos, assumidos como saberes e possibilidades em construção.

Por vivermos em um contexto digital, como darmos guarida a esta inserção? Como nos alfabetizarmos ante os múltiplos letramentos que se fazem necessários nos processos de aprendizagem da leitura e da escrita neste cenário? Que relações são desenvolvidas entre a escola e a linguagem musical? Que sincronias são constituídas entre a escola e a família no que se refere à linguagem musical? Como a linguagem musical entra e permanece na vida da criança? Como elas significam e reconhecem a linguagem musical no seu cotidiano? Essas e outras questões emergiram e permanecem após este estudo, provocando a nos ocuparmos delas.

A proposição, a problematização e as reflexões efetuadas nos permitem afirmar que, para conhecermos toda e qualquer linguagem, precisamos nela adentrar, buscando suporte e diálogo sistemático junto aos que dela se ocupam. Destacamos, outrossim, a necessária sintonia na formação das(os) professores(as) da Educação Infantil e Anos Iniciais do Ensino Fundamental, os quais promovem, de maneira formal, a iniciação às vivências fundamentais ao processo de desenvolvimento das potencialidades das múltiplas linguagens. Cabe-nos, na condição de professoras(es) pesquisadoras(es), a busca atenta às demandas que fluem, as quais requerem diálogo com as comunidades.

\section{Referências}

ALMEIDA, Berenice de. Encontros Musicais: Pensar e fazer música na sala de aula. São Paulo: Melhoramentos, 2009.

ÁVILA, Marli Batista; SILVA, Karen Batista Ávila. A música na Educação Infantil. In: NICOLAU, Marieta Lucia Machado; DIAS, Marina Célia Moraes Dias (org.). Oficinas de sonho e realidade na formação do educador da infância. 2. ed. Campinas: Papirus, 2003. p. 75-93. 
BELLOCHIO, Cláudia Ribeiro; FIGUEIREDO, Sérgio Luiz Ferreira de. Cai, cai balão... Entre a formação e as práticas musicais em sala de aula: discutindo algumas questões com professoras não especialistas em música. Música na educação básica, Porto Alegre, v. 1, n. 1, p.36-45, out. 2009.

BELLOCHIO, Cláudia Ribeiro; WEBER, Vanessa; SOUZA, Zelmielen Adornes de. Música e Unidocência: pensando a formação e as práticas de professores de referência. Rev. FAEEBA - Ed. e Contemp., Salvador, v. 26, n. 48, p. 205-221, jan./abr. 2017. Disponível em: $<$ https://www.revistas.uneb.br/index.php/faeeba/article/view/3816/2371>. Acesso em: 24 abr. 2020.

BRÉSCIA, Vera Pessagno. Educação Musical: Bases psicológicas e ação preventiva. 2. ed. Campinas: Átomo, 2011.

BRITO, Teca Alencar de. Música na educação infantil: propostas para a formação integral da criança. São Paulo: Peirópolis, 2003.

CANDAU, Vera Maria et al. Oficinas pedagógicas de direitos humanos. 3. ed. Petrópolis: Vozes, 1999.

CASTRO, Kátia Regina dos Santos et al. A linguagem musical e o desenvolvimento das múltiplas inteligências: um olhar sobre a educação infantil. In: FÓRUM INTERNACIONAL DE PEDAGOGIA, 8., 2016, Campina Grande. Anais... Campina Grande: Realize Editora, 2016. Disponível em: $<$ https://www.editorarealize.com.br/index.php/artigo/visualizar/24919>. Acesso em: 25 jul. 2020.

COSTA, Patricia. Lá vem o crocodilo... Exercícios vocais para crianças de 7 a 10 anos. Música na Educação Básica, Brasília, v. 5, n. 5, p. 78-87, 2013. Disponível em: $<$ http://www.abemeducacaomusical.com.br/revista_musica/ed5/artigo6.pdf $>$. Acesso em: 26 abr. 2020.

DAREZZO, Margareth. Canteiro: músicas para brincar. São Paulo: Ática, 2011.

FIGUEIREDO, Sérgio Luiz Ferreira de. Educação musical nos anos iniciais da escola: identidade e políticas educacionais. Revista da ABEM, Porto Alegre, v. 12, p. 21-29, 2005. Disponível em: $<$ http://www.abemeducacaomusical.com.br/revistas/revistaabem/index.php/revistaabem/ article/view/331>. Acesso em: 25 jul. 2020.

FREIRE, Paulo. A pedagogia da autonomia: saberes necessários à prática educativa. 7 . ed. Rio de Janeiro: Paz e Terra, 1997. 
LANDGRAF, Renata Mariano. PIBID Música na Educação Infantil: Uma experiência interdisciplinar a partir da construção de instrumentos musicais e objetos sonoros com materiais alternativos. In: ENCONTRO REGIONAL SUL DA ABEM, 17., 2016, Curitiba Anais... Curitiba, 2016. Disponível em: $<$ http://abemeducacaomusical.com.br/ conferencias/index.php/xviiregsul/regs2016/paper/viewFile/1762/790>. Acesso em: 25 jul. 2020.

MAFFIOLETTI, Leda de Albuquerque. Musicalidade ao longo da vida. In: ENCONTRO NACIONAL DE DIDÁTICA E PRÁTICA DE ENSINO, 15., 2010, Belo Horizonte.. Anais... Belo Horizonte, 2010, p. 3-12. Disponível em: $<$ https://pt.slideshare.net/ grupopesquisamusicauergs/musicalidade-ao-longo-da-vida>. Acesso em: 27 abr. 2020.

MORAES, Roque; GALIAZZI, Maria do Carmo. Análise Textual Discursiva: processo reconstrutivo de múltiplas faces. Ciências \& Educação, v 12, n 1, p. 117-128, 2006.

NÓVOA, Antônio. Desafios do trabalho do professor no mundo contemporâneo. São Paulo: SINPRO, jan. 2007. (Palestra).

PÉREZ GÓMEZ, Angel. A aprendizagem escolar: da didática operatória à reconstrução da cultura da sala de aula. In: GIMENO SACRISTÁN, José; PÉREZ GÓMEZ, Angel (org.). Compreender e transformar o ensino. Porto Alegre: Artes Médicas, 1998. p. 53-65.

REYS, Maria Cristiane Deltregia. Era uma vez... Entre sons, músicas e histórias. Música na Educação Básica, v.3 n. 3, p. 68-83, 2011. Disponível em: < http://abemeducacaomusical.com.br/ revista_musica/ed3/pdfs/artigo5_3.pdf > . Acesso em: 25 jul. 2020.

ROMANELLI, Guilherme Gabriel Ballande. Antes de falar as crianças cantam!: considerações sobre o ensino de música na educação infantil. Teoria e Prática da Educação, Maringá, v. 17, n. 3, p. 61-71, set./dez. 2014. Disponível em: $<$ http://periodicos.uem.br/ojs/index.php/TeorPratEduc/article/view/28208/pdf_69>. Acesso em: 26 abr. 2020.

ROMÃO, José Eustáquio. Pedagogia Dialógica. São Paulo: Cortez Editora, 2002.

SILVA, Cleidiane de Oliveira; CASTRO, Paula Almeida de. As cantigas de roda no contexto da Educação Infantil. In: CONGRESSO NACIONAL DE EDUCAÇÃO, 3., 2016 Natal. Anais... Natal: Realize, 2016. Disponível em:

$<$ http://www.editorarealize.com.br/editora/anais/conedu/2016/TRABALHO_EV056_MD1 _SA17_ID1304_04082016091518.pdf>. Acesso em: 25 jul. 2020. 
SIQUEIRA, Cláudio Alves; BONFIM, Evandro Luiz Soares. A música como estratégia utilizada na Educação Infantil e promotora da interdisciplinaridade: um olhar singular. EFACEQ: Revistas dos Discentes da Faculdade Eça de Queirós. Ano 6, n. 10, ago.2017.

TRINDADE, Azoilda Loretto da. Olhando com o coração e sentindo com o corpo inteiro no cotidiano escolar. In: TRINDADE, Azoilda Loretto da; SANTOS, Rafael dos (org.). Multiculturalismo: mil e uma faces da escola. Rio de Janeiro: DP\&A, 2000. p.7-16.

PAZ, Ermelinda Azevedo. Pedagogia musical brasileira no século XX: metodologias e tendências. Brasília: Musimed, 2000.

PRIETO, Heloisa; PUCCI, Magda. De todos os cantos do Mundo. São Paulo: Companhia das Letrinhas, 2008.

\footnotetext{
${ }^{1}$ Artigo que sistematiza experiência vivenciada por meio de Projeto de Cultura, financiado por Edital da UFFS 2018/2019.

${ }^{2}$ Parâmetros do som apresentados em Brito (2003).

${ }^{3}$ Antônio Lucio Vivaldi (1678-1741), compositor e músico do estilo barroco tardio, oriundo da República de Veneza na Itália.

${ }^{4}$ As falas da roda de conversa foram gravadas e transcritas, das quais alguns destaques somam-se às demais contribuições do instrumento de avaliação descritivo.

${ }^{5}$ Grifos nossos. Excertos da avaliação realizada pelos interlocutores por meio de instrumento específico e por meio de roda de conversa: exercícios realizados em parceria junto às(aos) partícipes das oficinas.

${ }^{6}$ Os registros das avaliações foram organizados alfabeticamente.
} 